\title{
CONSUMPTION EXTERNALITIES, COORDINATION, AND ADVERTISING*
}

\author{
By Ivan Pastine and Tuvana Pastine ${ }^{1}$ \\ Bilkent University, Turkey, and CEPR
}

\begin{abstract}
The aim of this article is to demonstrate that advertising can have an important function in markets with consumption externalities apart from its persuasive and informative roles. We show that advertising may function as a device to coordinate consumer expectations of the purchasing decisions of other consumers in markets with consumption externalities. The implications of advertising as a coordinating device are examined in the pricing and advertising decisions of firms interacting strategically. Although, at times, the one-period advertising expense can exceed the one-period monopoly profit, in equilibrium, consumers will pay a premium for the more heavily advertised brand.
\end{abstract}

\section{INTRODUCTION}

In many markets, a consumer's choice of brand depends, in part, on her expectation of the purchasing decisions of other consumers. When consumers care about the behavior of others, either due to social influences or network externalities, there are often multiple equilibria in the consumers' consumption decisions. In this article, we show that in markets with consumption externalities, it is possible to view advertising as a device that helps consumers to coordinate their purchases, and hence realize the externality. Since firms have preferences over which of the products are selected, they have incentives to provide devices to coordinate consumer expectations on their own brand. The aim of this article is to demonstrate that even when consumers are fully rational and have common knowledge of the existence, characteristics, and prices of the products, advertising can still have an important role to play.

The idea can be illustrated by a simple two-consumer example. Consider two school children at the end of summer. The parents of each child are going to buy a pair of sneakers for the start of the school year. There are two brands available that are, ex ante, identical. However, ex post, each child will prefer to wear the popular

\footnotetext{
* Manuscript received January 1999; revised January 2000.

${ }^{1}$ This article has been presented at the 1999 North American Winter Meetings of the Econometric Society, the 1998 Annual Conference of the European Association for Research in Industrial Organization, the 1998 North American Summer Meetings of the Econometric Society, the 1997 Congress of the European Economic Association, the 1997 Bogaziçi Workshop on Economic Design, the 1997 International Meeting of the Society for the Advancement of Economic Theory, and Georgetown University. We would like to thank the seminar participants for helpful comments. Responsibility for errors remains our own. E-mail: pastine@bilkent.edu.tr and tuvana@bilkent.edu.tr.
} 
brand, the brand that the other child is wearing. The problem can be written in strategic form as

\begin{tabular}{lll}
\hline & Brand A & Brand B \\
\hline Brand A & 10,10 & 0,0 \\
Brand B & 0,0 & 10,10 \\
\hline
\end{tabular}

There are two equilibria in this game where demand is coordinated and the consumption externality is realized. In one of them, both children get brand A and in the other both children get brand $\mathrm{B}^{2}$ There is also a third equilibrium where the children mix between $\mathrm{A}$ and $\mathrm{B}$ with even probabilities. The mixed-strategy equilibrium yields lower expected payoffs for both the children.

The multiplicity of equilibria presents an equilibrium-selection problem. Clearly, in the example of the school children, the problem could be solved through direct communication between the consumers. However, as the number of consumers increases, this type of direct communication becomes more difficult. In the absence of direct communication between the consumers, they would want to find some other device to coordinate their purchases on one of the brands. The more interesting cases arise when consumers use the observed actions of the firms themselves to coordinate their expectations. And, in fact, firms have incentives to provide devices for consumers to coordinate their expectations, even costly devices such as advertising, since firms have strict preferences over each of the equilibria.

This provides a useful framework for understanding much observed advertising. For instance, although young people are not the wealthiest group of consumers, a disproportionate amount of advertising is aimed at them, presumably because they can be more easily swayed by advertising. However, this need not mean that young people are somehow less rational than their elders. It could simply be that they care more about the behavior of others. If youngsters are more vulnerable to social pressures, then coordination of their expectations is central to market success. This presents an important role for advertising, not to inform them, nor to persuade them that one brand is somehow intrinsically different from other brands, but to convince them that others will be buying it as well.

In markets with network externalities, there also is an incentive for a firm to provide a device to coordinate consumer expectations. The decision whether to invest in OS2 or, alternatively, in Windows 95 is obviously affected by the expectation of the consumer as to which operating system will be more widely adopted. It is possible, therefore, that the large advertising campaign for the launch of Windows 95 was not merely an attempt to inform consumers of the existence and price of the product, but also a device to coordinate consumer expectations on the brand.

\footnotetext{
${ }^{2}$ Multiple equilibria often arise in markets with consumption externalities. Becker (1991) points out that goods that have an element of social interaction in their consumption are likely to exhibit consumption externalities and multiple equilibria. For example, eating at a restaurant or seeing a Broadway play is more enjoyable if one is not the only customer.
} 
There might be a misconception in the literature about whether advertising can help to achieve demand coordination in markets with consumption externalities. In the words of Bagwell and Ramey (1994a, p. 157), “. . a firm can use advertising only to signal its own choices, and not the choices of other consumers that are the source of network benefits." Although it is true that a firm cannot use advertising to signal the choices of other consumers, in this article we will show that advertising can shape the expectations of consumers about the purchasing behavior of other consumers.

Consider the problem of a consumer who would like to buy a widely used product, but does not know which brand it is going to be. He realizes that other consumers are in a similar situation. Momentarily, suppose that two brands are available at the same price ${ }^{3}$ but that one brand is more heavily advertised. The fact that advertising is publically observable makes it a likely candidate for use as a coordinating device. Moreover, since advertising is expensive for firms, a sophisticated consumer can reason that the firm invests in advertising only if it expects advertising to result in increased sales. So, it will be in the best interest of the consumer to purchase the more heavily advertised brand, vindicating the firm's investment in advertising.

In this article, we are looking at advertising as a coordination device in the sense of selecting an equilibrium where demand is coordinated, ${ }^{4}$ and thus achieving positive consumption externalities. This is an issue because in these markets, there are often other equilibria where consumers do not achieve the consumption externalities. Hence, in the absence of direct communication between consumers, demand coordination is a nontrivial service. The same multiple-equilibria issues that create this equilibrium-selection problem also raise the question of whether players will be able to coordinate on playing any equilibrium. We will not be examining coordination in this sense here, but will be assuming throughout that with or without advertising, an equilibrium will be played.

We construct a simple, infinite-horizon model where consumers care about the behavior of other consumers, and identical duopolistic firms must make a short-run commitment to the level of advertising. We show that it is rational for consumers to use both advertising and price information to coordinate their expectations about the purchasing behavior of other consumers. In markets with consumption externalities, competition between oligopolistic companies can manifest itself in the form of intense and costly advertising wars. At times, the one-period advertising expense can exceed the one-period monopoly profit. Advertising competition will decrease price competition and consumers will pay a premium for the more heavily advertised brand.

It is important to stress at this point that the goal of this article is to try to understand observed advertising. We do not aim to describe how consumers should coordinate their expectations. Nor do we contend that coordinating advertising will always be observed in markets with positive consumption externalities. What we do argue is that it is quite reasonable to think that advertising would often be seen in these markets, and that seeing it in this light makes much observed advertising more understandable.

\footnotetext{
${ }^{3}$ The pricing decision will be analyzed shortly.

${ }^{4}$ Coordination in this sense is prominent in Bagwell and Ramey (1994a,b).
} 


\section{FRAMEWORK}

In order to focus on this previously unanalyzed function of advertising, we construct a simple infinite-horizon model that abstracts from all other roles of advertising.

2.1. Abstracting from the Previous Literature. "Persuasive advertising" is one view of advertising that has been examined in the literature. Advertising may be able to increase the demand for a product by persuading consumers that the product is desirable. This can be done either by systematically tricking them into believing that products are different although in reality they are fundamentally identical (see, e.g., Galbraith, 1967; Solow, 1967), by crowding out information from the minds of boundedly rational consumers (Ishigaki, 1999), or by changing the preferences of rational consumers, as in Dixit and Norman (1978). Advertising may also persuade consumers that a product is desirable if advertising and the good are compliments in the consumer's utility function, as analyzed by Becker and Murphy (1993). We abstract from this role for advertising by assuming fully rational consumers whose preferences are not affected by advertising.

Another concept of advertising, "informative advertising," provides direct information on the existence and characteristics of the product, such as price and quality. This type of advertising has been studied by Butters (1977), Grossman and Shapiro (1984), Meurer and Stahl (1994), Robert and Stahl (1993), Stahl (1994), and Stegeman (1991). In these articles, advertising helps to match buyers and sellers by solving an information problem. Bagwell and Ramey (1994a), Kihlstrom and Riordan (1984), Milgrom and Roberts (1986), and Nelson (1974) show that even when advertising does not directly communicate the characteristics of the product, it can still communicate them implicitly. Advertising can be a mechanism through which firms can signal their type to consumers. Consumers can then use this information to infer the quality or price of the goods offered by each company. When advertising is used as a signal in this way, it is possible for it to help match buyers with sellers, or to coordinate consumer purchases on the products of the low-cost firm. This signaling is possible because different types of firms have different returns to advertising, and, hence, advertising can reveal the type of the firm. We abstract from this informative role of advertising, either directly or through signaling, by assuming identical firms and common knowledge of the existence, characteristics, and prices of the products.

Bagwell and Ramey (1994a,b) studied a framework where satisfactory communication of price information is not possible, due to a complex pricing structure. They showed that advertising can help to achieve scale economies when the exogenously assumed pricing rule dictates that firms quote lower prices when they expect to sell a higher quantity. In equilibrium, the high-advertising firm offers low prices and advertising leads to a more concentrated market structure and greater social welfare. By assuming common knowledge of prices, we also abstract from this previously analyzed coordinating role of advertising. We, therefore, abstract from all the previously examined functions of advertising.

2.2. The Model. In order to examine these issues in a dynamic setting, we adopt a model in the spirit of Maskin and Tirole's (1988) dynamic price competition article. 
By restricting attention to Markov strategies and assuming that firms must make a two-period commitment to their prices, Maskin and Tirole are able to gain useful insights into firm incentives in dynamic price competition. In our article, the problem is compounded: We must examine both prices and advertising levels through time. Restricting attention to Markov-perfect equilibria and assuming an exogenous twoperiod commitment (in this case to advertising levels), we gain enough structure to make the problem tractable.

The cost of this approach is that it restricts the potential strategies of the players. The restriction to Markov strategies precludes many types of collusive strategies and much of the potential for reputation building. ${ }^{5}$ Likewise, although the assumption of short-term commitments is reasonable, one would certainly think that in reality the length of the commitment would be chosen endogenously. Nevertheless, it is hoped that the tractability gained by these restrictions will yield useful insights into firm incentives in dynamic advertising competition.

Consider a very simple structure that captures the consumers' problem in a market with positive consumption externalities. In each period, a unit continuum of homogenous consumers have unit demands for a nondurable good. ${ }^{6}$ Consumers observe the prices and the levels of advertising of duopolistic firms, and they simultaneously choose a brand maximizing their expected utility from the purchase. The goods produced by the two companies are identical and the consumers know this. However, ex post, the value of the good to the consumer depends on the proportion of consumers that chose that brand as well. Consumers cannot communicate with each other prior to their purchases. Ex post, each consumer $i$ observes the fraction $\lambda^{i} \in[0,1]$ of consumers who purchased the same brand and derives utility,

$$
U^{i}= \begin{cases}G\left(\lambda^{i}\right)-P & \text { from a brand purchased at price } \mathrm{P} \\ 0 & \text { if the consumer decided not to buy }\end{cases}
$$

The valuation $G\left(\lambda^{i}\right)$ is a weakly increasing function of the fraction of consumers who purchased the same brand as consumer $i$, and $G(0)<G(1)$. Notation is simplified by defining $\underline{G} \equiv G(0)$ and $\bar{G} \equiv G(1)$. This simple utility function captures network externalities and the "bandwagon effect" where the demand for a commodity increases because others are consuming it. ${ }^{7}$

The game between the consumers may have more than one Nash equilibrium. If the prices chosen by the two firms are sufficiently close, it will be an equilibrium for everyone to buy one brand and it will also be an equilibrium for everyone to buy the other brand. The firms will, however, have strict preferences over the equilibria.

\footnotetext{
${ }^{5}$ Although classic trigger strategies are precluded by the Markov restriction, it does not preclude many similar "punishment" strategies. See Halperin (1990) and the discussion of kinked demand equilibria in Maskin and Tirole (1988) for interesting examples.

${ }^{6}$ For a static model with heterogeneous consumers, see Pastine and Pastine (1999).

${ }^{7}$ Similar consumption externalities have been studied by Becker (1991), Farrell and Saloner (1985), Frank (1985), and Schelling (1978). In another setting, Pesendorfer (1995) shows that the fashion industry may also be driven by consumption externalities due to social influences when coordination is via price information alone.
} 
There are two identical firms with constant marginal cost $c \in[0, \bar{G})$. It is assumed that the externality is great enough, or marginal cost high enough, that the potential value of the externality, $[\bar{G}-\underline{G}]$, in this market is greater than the intrinsic value over cost of the product, $[\underline{G}-c]$. Each firm must make a short-run commitment to the level of the advertising. Once the firm decides on the level of the advertising, it sustains that level of advertising for two periods. Without loss of generality, assume that the advertising cost $A$ is paid up front. Therefore, the one-period profit $\pi$ in the period the advertising decision is initiated is equal to total revenue less production costs minus the advertising expense. And the firm's one-period profit if the advertising decision was made the previous period is just total revenue less production costs.

Since firms have a short-run commitment to advertising, there are potentially two possible timings in the game between firms: They could alternate in the advertising decision, or they could choose their levels of advertising in the same period. Initially, we will model the duopoly game with exogenous timing, assuming that firms alternate in the advertising decision. In odd-numbered periods $t=1,3,5, \ldots$, firm 1 chooses its advertising that remains unchanged until period $t+2$. Firm 2 chooses its advertising only in even-numbered periods $t=0,2,4, \ldots$ This exogenous timing assumption is relaxed in the Appendix, where it is shown that for many of the interesting cases, firms will indeed choose to alternate in the advertising decision. The advertising space is assumed to be discrete with a step size of $k$. This allows a concrete meaning to "out-advertising" a rival.

Firms maximize the expected present value of profits, and they discount the future at the same rate $\delta \in(0,1)$. In the beginning of each period, the firm whose turn it is to choose a new level of advertising does so. The rival observes this decision and then both firms quote their prices simultaneously. Consumers then observe the levels of advertising and prices quoted by the firms. They make their purchasing decision maximizing their expected utility. At the end of the period, consumers observe the purchases of other consumers and derive utility accordingly.

We focus attention on Markov-perfect equilibria where strategies for strategic players depend only on payoff-relevant state variables. The maximized expected present value of the game to firm 1 , when firm 1 is about to move in its advertising decision is given by $V^{1}(A)$, where $A$ is the level of advertising that firm 2 chose in the last period, and is therefore committed to in this period,

$$
V^{1}(A)=\max _{A^{1} \in \mathbb{I} k}\left\{\max _{P^{1} \in[0, \infty)} E_{P^{2}}\left[\pi^{1}\left(P^{1}, P^{2}, A^{1}, A\right)+\delta E_{A^{2}} W^{1}\left(A^{1}, A^{2}\right)\right]\right\}
$$

$W^{1}\left(A, A^{2}\right)$ is the maximized expected present value of the game to firm 1 when firm 1 is committed to advertising $A$ and firm 2 has just chosen its level of advertising $A^{2}$,

$$
W^{1}\left(A, A^{2}\right)=\max _{P^{1} \in[0, \infty)} E_{P^{2}}\left[\pi^{1}\left(P^{1}, P^{2}, A, A^{2}\right)+\delta V^{1}\left(A^{2}\right)\right]
$$

The expectations in both equations are taken over firm 2's equilibrium strategies. Symmetric equations describe firm 2's optimization problem. In this structure, the only payoff-relevant state variable in the advertising decision is the level of advertising that the firm's rival is committed to. 


\section{EQUILIBRIUM}

Suppose that a firm did mount a large, costly advertising campaign. For an equilibrium without advertising to survive, the off-equilibrium strategies require that consumers ignore this advertising. This means that consumers must assume that any observed advertising was a mistake on the part of the firm. However, it seems unlikely that a consumer would blithely ignore the actions of firms when forming her expectations, particularly when confronted with a costly advertising campaign. A consumer could reason that the firm rationally invested in the advertising campaign because it believes that consumers were going to use advertising as a coordinating device. If others are using advertising as a coordinating device, then the consumer would use this information in forming his own expectations. ${ }^{8}$

In this section, we show that it is rational for consumers to use advertising as a coordinating device. In equilibrium, firms' pricing and advertising strategies are such that it is always in an individual consumer's best interest to purchase the more heavily advertised brand.

3.1. The Pricing Decision. It is useful to start the analysis by considering a subgame where firms are deciding on prices. Suppose that going into the pricing subgame, the firms have different levels of advertising. In this case, consumers may expect that the firm with higher advertising will attract the coordinated demand: They will anticipate that the good will have the value $\bar{G}$ if they purchase it from the firm with high advertising and that the good will have the value $\underline{G}$ if they purchase it from the firm with low advertising. To be competitive, the firm with low advertising would have to offer a lower price than the firm with high advertising. However, if the firm's marginal cost is greater than $\underline{G}$, then even if the low advertising firm sets a price equal to the marginal cost it cannot offer positive consumer surplus. Therefore, the high-advertising firm can capture the coordinated demand with a price equal to the monopoly price, $\bar{G}$. In this case, the firm with higher advertising can extract all the consumer surplus. The high-advertising firm sets price equal to the monopoly price, and any price greater than or equal to marginal cost, including the monopoly price, is sustained as an equilibrium strategy for the low-advertising company. Consumers will coordinate on the good produced by the firm with high advertising. The consumer receives the value $\bar{G}$ from the purchase, at the monopoly price however, since advertising curtails price competition.

If $\underline{G}>c$, then there will be price competition. Consumers will purchase from whichever firm offers higher expected consumer surplus. In this case, there cannot be a Nash equilibrium where the low-advertising firm offers a price above marginal cost. Assume that the low-advertising firm did offer a price above

\footnotetext{
${ }^{8}$ Firms in markets with significant consumption externalities often try to encourage this type of reasoning. In the early months of 1995, during the height of its advertising campaign for OS/2, IBM frequently cited its $\$ 500$ million investment in the operating system as evidence of its "commitment" to the product. When Windows 95 was launched in August 1995, Microsoft widely publicized that it was spending \$200 million on advertising alone. See, for example, Panettieri (1995) and Rebello and Kuntz (1995).
} 
marginal cost. If the high-advertising firm was offering the same or greater consumer surplus, the firm with low advertising could increase its profits by lowering its price. If the firm with higher advertising was offering a lower consumer surplus, the high-advertising company could increase its profits by lowering its price. Therefore, in equilibrium, the low-advertising firm will set $P=c$ offering a consumer surplus of $[\underline{G}-c]$. The high-advertising firm must set its price low enough so that consumers get at least as much consumer surplus as they would from the low-advertising firm. This implies that the equilibrium price for the high-advertising firm is equal to $[\bar{G}-\underline{G}]+c$.

The high-advertising firm will capture the coordinated demand and, before advertising costs, the Nash strategies imply that the firm receives the one-period profit given by price minus marginal cost,

$$
\pi^{*} \equiv \bar{G}-\max \{c, \underline{G}\}
$$

Notice that $\pi^{*}>0$ since $\bar{G}>c$ and $\bar{G}>\underline{G}$.

It is also possible that the firms have equal levels of advertising going into the pricing subgame. The equilibrium will depend on how consumers are forming their expectations of the behavior of other consumers.

One natural possibility is that consumers believe that if both firms have the same level of advertising, then the lowest priced product will attract the coordinated demand. If one firm offered a lower price, the consumer would prefer the cheaper brand since it would give a higher consumer surplus. However, this is not only true for a single consumer but it is valid for all other consumers as well. This implies that the consumers would be inclined to buy the cheaper brand, not only because the lower price yields a higher consumer surplus, but also because of the positive consumption externalities. In other words, consumers would anticipate that the brand with the lower price would capture the coordinated demand, and they would receive value $\bar{G}$ from consuming that brand and only $\underline{G}$ from consuming the other brand. Therefore, the pricing problem for firms is simply Bertrand price competition, which results in marginal cost pricing. Hence, when firms have equal levels of advertising, or when consumers are not using advertising levels in forming their expectations, in equilibrium, both firms set price equal to marginal cost. Looking at consumer purchases, there are many possible equilibria, but if we restrict attention to anonymous equilibria by requiring that identical firms be treated the same, consumers will be indifferent between purchasing brand A and brand B. Since there is a continuum of homogenous consumers, in expectation the two brands sell the same amount and consumers receive value $G(1 / 2)$ from the purchase. ${ }^{9}$ If $c>G(1 / 2)$, the price will be too high to justify the purchase and there will be no sales. If $G(1 / 2) \geq c$, then it is an equilibrium for consumers to buy the good and they

\footnotetext{
${ }^{9}$ Since there is a continuum of consumers, there is a continuum of equilibria (both pure and mixed strategy) that yield this outcome.
} 
will split their purchases between the two brands. ${ }^{10}$ Defining $\tilde{\pi}$ as a firm's one-period profits before advertising expenses when both firms have the same level of advertising or when consumers are not using advertising levels in forming their expectations, $\tilde{\pi}=0$. Since $\tilde{\pi}=0$ there is a potential profit to be made by a firm if it can coordinate consumer expectations on its product. The incentives of firms are related to the difference between the value of the product when consumption is fully coordinated on their product and value of the product when consumers coordinate on the rival's brand. However, the value of coordination to consumers is related to the value that was added by moving from an equilibrium with uncoordinated demand to an equilibrium with coordination.

Another possibility is that when firms have equal levels of advertising, consumers may expect the higher-price brand to capture the coordinated demand instead of the low-price brand. In this case there will be a different equilibrium in the pricing subgame. However, it continues to be true that having higher advertising than its rival will give a firm an advantageous position in the price competition phase compared with having equal advertising levels.

If both firms have equal levels of advertising and $\underline{G} \leq c \leq \bar{G}$, one firm charging $\bar{G}$ and the other setting any price greater than or equal to marginal cost can be sustained in an asymmetric equilibrium. However, the only anonymous equilibrium involves both firms setting price equal to $\bar{G}$. Since in this case firms are identical in every respect, in an anonymous equilibrium, the consumers will split between the brands. The consumer's expected utility value from the purchase will be $G(1 / 2)$ minus the purchase price. When $G(1 / 2)<\bar{G}$, the purchase will result in negative consumer surplus; hence, there will be no purchases and $\tilde{\pi}=0$. Here, the firm has an incentive to out-advertise the rival, since through higher advertising, the firm can coordinate consumer expectations charging the price $\bar{G}$, while the rival's high marginal cost precludes meaningful price competition. If, however, $G(1 / 2)=\bar{G}$, each firm will be selling to half of the market, consumers will get no consumer surplus and $\tilde{\pi}=(\bar{G}-c) / 2$. In this case too, the firm has an incentive to out-advertise the rival, $\tilde{\pi}<\pi^{*}$, since with higher advertising it is able to double its sales without reducing its price.

Now, let us analyze the case where $\underline{G}>c$. When firms have the same level of advertising, there is no pure-strategy Nash equilibrium in the pricing subgame. Suppose that firm A sets price equal to $\bar{G}$ and firm B sets a lower price. First, one might think that A would get the coordinated demand since it offers the higher price. However, if firm B's price is low enough, then the consumer expectation that A will

\footnotetext{
${ }^{10}$ This equilibrium is not necessarily unique. If $\underline{G} \leq c \leq G(1 / 2)$, then there is also an equilibrium where no consumer purchases either good. In Rohlfs (1974), this issue takes center stage. He points out that the existence of these two equilibria makes it difficult to get a new product off the ground. In his article, the product of interest is a new communication service which has a low value if nobody else subscribes, since that would imply that there would be nobody to communicate with; however, the service is valuable if it is widely adopted. He then examines various pricing and distribution mechanisms that a firm could use to move from the equilibrium with no purchases to the Paretosuperior equilibrium with adoption of the product. One of the insights of our article is that advertising may also have an important role in solving this type of problem. Advertising can be useful not just to inform people of the existence of the product, but also to convince them that others will be purchasing it, and hence that it will have a high value to the consumer.
} 
get the coordinated demand is not rational. If B sets price lower than $\underline{G}$, when A has price equal to $\bar{G}$, even if an individual consumer expects others to purchase $\mathrm{A}$, she will prefer to purchase $\mathrm{B}$, since $\mathrm{B}$ gives a higher consumer surplus. However, this is true for all consumers, so firm B will capture the high demand. So expecting A to be the popular brand will not be rational. But notice that given that B charges $\underline{G}$, it would be no longer optimal for A to charge $\bar{G}$. It would prefer to lower its price below $\bar{G}$, offering slightly a higher consumer surplus, coordinating consumers on its brand, while charging higher than B. But B would then prefer to change its price. Hence, when $\underline{G}>c$, there is no pure-strategy Nash equilibrium in the pricing subgame. Consider then the expected payoffs in a symmetric mixed-strategy equilibrium. Define $\bar{p}$ as the supremum of the support of the mixed strategy. Also, define $\tilde{p}$ as the highest price that effectively undercuts $\bar{p}$ (making it worthwhile for a consumer to purchase the lower-price product despite her initial belief that the higher-priced product will capture the coordinated demand). Then, $\tilde{p}$ must be in the support and it is defined by $\bar{G}-\bar{p}=\underline{G}-\tilde{p}$. Rearranging the terms, $\tilde{p}=[\bar{p}-\bar{G}]+\underline{G}$. Since $\bar{p} \leq \bar{G}, \tilde{p} \leq \underline{G}$, and $\tilde{p}$ is in the support of the mixed strategies, the expected payoff from the pricing subgame is $0<\tilde{\pi} \leq[\underline{G}-c]$. This gives the firm an incentive to out-advertise the rival, capturing the coordinated demand setting price equal to $[\bar{G}-G]+c$, and receiving a profit $[\vec{G}-\underline{G}]$, before the advertising expense. Since the potential value of the externality $[\bar{G}-\underline{G}]$ in this market is greater than the intrinsic value over cost of the product $[\underline{G}-c]$, the firm would rather find itself in a state where it has higher advertising than the state where firms have the same level of advertising.

Thus, in either case (coordinating on the low-priced brand or coordinating on the high-priced brand), if a firm can out-advertise its rival, it can gain an advantage in the price-competition phase and receive profits given by (4) before advertising expenses. In both cases, this is strictly greater (before advertising expenses) than the expected profit it could receive if it did not out-advertise its rival $\tilde{\pi}^{11}$

\footnotetext{
${ }^{11}$ It is also possible that consumers use a combination of price and advertising levels to coordinate their purchases. For example, they could use an indicator function $I=\alpha A-\beta P$ and coordinate on whichever firm had a higher indicator. In this case, firm incentives are nearly identical to the incentives analyzed in the text. Going into the price-competition phase, whichever firm had higher advertising could get away with a somewhat higher price than its rival and still receive the coordinated demand, giving it an incentive to out-advertise its rival. The same logic as presented in the text yields a price equilibrium of $P=c$ for the low-advertising company and $P=\min \left[(\alpha / \beta)\left(A^{\prime}-A^{\prime \prime}\right)+c\right.$, $\min [\bar{G}, \bar{G}-\underline{G}+c]]$ for the high-advertising company, where $A^{\prime}$ is the higher advertising and $A^{\prime \prime}$ is the lower advertising level. If $\alpha<\beta$, the cost of advertising to gain advantage in the price-competition phase will be prohibitive, and neither firm will advertise. If $\alpha \geq \beta$, it will be worthwhile to out-advertise the rival (at low levels of advertising) just as in the text, and when firms choose to do so, they will increase the level of advertising by enough to gain complete advantage in the price-competition phase, setting advertising at $A^{\prime}=A^{\prime \prime}+(\beta / \alpha)\{\min [\bar{G}-c, \bar{G}-\underline{G}]\}$ Thus, one could drop the discrete advertising space assumption and large $\alpha$ or small $\beta$ could replace our assumption of small $k$. In that case, the equilibrium of the complete game would mirror the equilibrium found in the text.

More generally, consumers may use a nonlinear combination of advertising and price to coordinate their purchases. Although the basic incentive to out-advertise the rival in order to gain an advantage in price competition would remain (as long as the indicator was increasing in advertising), the equilibrium would be considerably more complex. With nonlinear indicator functions, the amount that the firm would choose to out-advertise its rival would no longer be state independent, which is critical to the derivation of equilibrium, but not to the basic message of the article.
} 
3.2. The Advertising Decision. When a firm is choosing its level of advertising, it can use backward induction to infer the solution to the pricing subgame. Therefore, it knows that its expected current-period profit, $\pi$, will be given by

$$
\pi(A ; \tilde{A})= \begin{cases}-A & \text { if } A<\tilde{A} \\ \tilde{\pi}-A & \text { if } A=\tilde{A} \\ \pi^{*}-A & \text { if } A>\tilde{A}\end{cases}
$$

A is the firm's choice of advertising and $\tilde{A}$ is the level of advertising that the rival is committed to. If the firm chooses lower advertising than its rival, $A<\tilde{A}$, the rival captures the coordinated demand. If the firm chooses $A=\tilde{A}$, firms engage in fierce price competition (how fierce depends on the coordinating device used by consumers) and receive relatively low expected profits. However, when the firm out-advertises its rival, $A>\tilde{A}$, it captures the coordinated demand. In this case, the firm receives profits of $\left(\pi^{*}-A\right)$ by coordinating consumer expectations on its product and by offering them a deal that gives them slightly higher consumer surplus than they can get with the other firm. ${ }^{12}$

So, it is natural for firms to consider advertising more than their rival. Once the firm out-advertises its competitor, it can attract the coordinated demand and charge a relatively high price. In the subsequent discussion, we show that this incentive leads to advertising wars. In this dynamic advertising competition, firms successively increase the level of advertising in order to coordinate consumer expectations on their own brand. Eventually, however, advertising competition becomes too costly for firms and they are inclined to revert to low levels of advertising. Nevertheless, each firm would like the other to lower its advertising first, leaving the firm in temporary, but profitable, control of the market. This results in a war of attrition, where each firm advertises in order to induce its rival to move to the relenting phase. Firms may accept a lower profit today in hopes of making a killing in the future. At some critical high level of advertising, however, it is worth ending the war, even when it is known with certainty that the rival will give up in the next period. ${ }^{13}$ In Figure 1, a typical time-path of advertising is depicted. The figure plots the level of the state variable. Firms successively raise the level of advertising until it reaches a critical point $\bar{A}$. At this level of advertising, firms are faced with two opposing tensions. Since the advertising competition is expensive, current period profits are low. So there is an incentive to relent and move to the beginning of the war with its low advertising and high profits. By relenting, the firm can enjoy these profits in the

\footnotetext{
12 When advertising is used as a device to coordinate consumer expectations, and either consumers coordinate on the low-priced brand when advertising levels are equal, or consumers coordinate on the high-priced brand when advertising levels are equal and $\underline{G} \leq c$, then there cannot exist a symmetric equilibrium with stable levels of advertising. Consider a level of advertising $A^{f}>0$. $A^{f}$ cannot be the best response to $A^{f}$ since in either case $\tilde{\pi}=0$, yielding negative profits due to the cost of advertising. However, the firm could always get zero profit by setting its advertising at zero. Zero advertising for both firms cannot be a stable equilibrium either, since responding to zero advertising with zero advertising results in fierce price competition and zero profits. Therefore, for $k<\pi^{*}$, the firm could do better by setting a positive level of advertising, $k$. It would then enjoy profit of $\pi^{*}$ minus $k$. In the future, the worst that could happen would be reverting to zero profits, since advertising zero would always be an option.

${ }^{13}$ Enrico and Kornbluth (1986) provide a fascinating account of the inner workings of such advertising wars of attrition in the soft-drink market.
} 


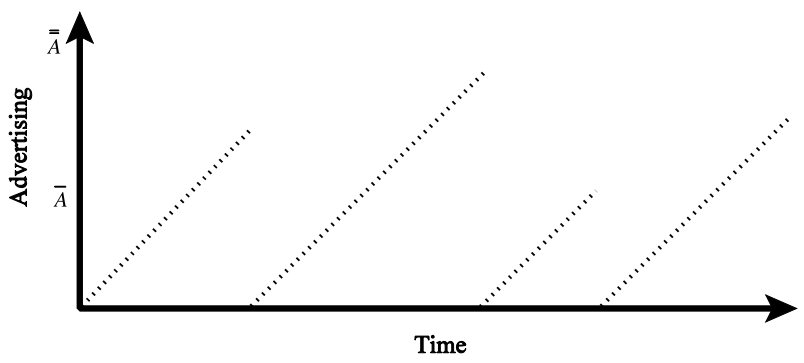

Figure 1

A TYPICAL TIME PATH OF ADVERTISING

near future. However, since the relenting firm leaves its rival in temporary command of the market, each firm would like the other to relent first. The firm that gives in must wait two periods after relenting before it can out-advertise its competitor. On the other hand, if the rival relents first, the firm will capture the coordinated demand for two periods with negligible advertising costs. Therefore, both firms try to induce the other to relent first. The firm considers increasing the level of advertising by $k$, because it believes that there is a chance for the rival to relent first. The rival also believes that there is a positive probability that the firm will relent first. So, the firms engage in a war of attrition where the duration and intensity of the advertising competition is stochastic in a deterministic environment. The war ends with certainty only if advertising reaches the level $\overline{\bar{A}}$ where it is so high that the cost of increasing advertising overwhelms the benefits of inducing the other firm to relent.

In this simple model, notice that the swings in market share and advertising are quite dramatic. Naturally, in a more realistic model with heterogeneous consumers, the changes in market share would not be as severe. ${ }^{14}$ Also, notice that in reality the informative, persuasive, and coordinating roles of advertising are likely to coexist. Hence, even when firms relent in the coordination competition, they would still continue to advertise a positive amount for the other functions of advertising.

Below, we define the symmetric dynamic reaction functions that form a Markovperfect equilibrium and yield advertising wars of the nature described above.

Claim 1. For small $k$, there exists a symmetric equilibrium where

$$
R(A)=\left\{\begin{array}{cll}
A+k & & \text { with probability } p(A) \\
0 & \text { with probability }(1-p(A))
\end{array}\right\} \begin{aligned}
& \text { for } \bar{A}>A \geq 0 \\
& \text { for } \overline{\bar{A}}>A \geq \bar{A} \\
& \text { for } A \geq \overline{\bar{A}}
\end{aligned}
$$

$R(\cdot)$ is the symmetric dynamic reaction function of the firms where $\{R, R\}$ forms a Markov-perfect equilibrium. If the rival's advertising is in the range $\bar{A}>A \geq 0$, the

\footnotetext{
${ }^{14}$ In Pastine and Pastine (1999), we examine advertising competition in a static model with heterogeneous consumers and show that the same incentives arise with less than complete coordination.
} 
firm prefers to increase advertising by $k$. If the rival's advertising is in the range, $\overline{\bar{A}}>A \geq \bar{A}$, the firm is indifferent between relenting and raising advertising by $k$. With probability $p(A)$, the firm relents. And with probability $[1-p(A)]$, the firm increases the level of advertising by $k$. So, during the mixed-strategy phase, the duration of the war is not known with certainty. There is a positive probability of each firm relenting first. However, if advertising ever reaches a level $A \geq \overline{\bar{A}}$, the firm prefers relenting even though it is known with certainty that the rival would have relented if the firm had stayed in the war. To prove Claim 1, we have to show that there exists $\bar{A}, \overline{\bar{A}}$, and a set of probabilities $p(A)$ for $\overline{\bar{A}}>A \geq \bar{A}$ so that $\{R, R\}$ is a Markov-perfect equilibrium. We first study conditions that must be satisfied for equilibrium. Then, in the Appendix, we demonstrate that the proposed strategies form a Markov-perfect equilibrium when these conditions are satisfied and prove the existence of $\bar{A}, \overline{\bar{A}}$, and $p(A)$, satisfying these conditions.

3.3. Equilibrium Conditions. In the Appendix, we establish a lemma showing that the valuation function $V(\cdot)$ is nonincreasing. Using this, we can examine the values characteristic of $\bar{A}, \overline{\bar{A}}$, and $p(A)$.

Claim 2. In advertising wars, the level of advertising can be as high as

$$
\left[(1+\delta) \pi^{*}+\delta^{2}(V(0)-V(k))\right]
$$

which is strictly greater than $\pi^{*}$. This expression can be greater than the one-period monopoly profit.

Proof. Advertising can be as high as $\overline{\bar{A}}$. At the state $\overline{\bar{A}}-k$, which is during the mixed-strategy phase, the firm is indifferent between relenting and increasing the level of advertising to $\overline{\bar{A}}$. If the firm relents, it has to stick to the low level of advertising for two periods and, therefore, does not collect any profits for two periods. Hence, if the firm relents, the expected value of the game is $\delta^{2} V(k)$, since $k$ is its rival's best response to zero advertising. If the firm advertises $\overline{\bar{A}}$, the rival's best response is to relent. Therefore, when the firm advertises $\overline{\bar{A}}$, the expected value of the game is given by $\left[\pi^{*}-\overline{\bar{A}}+\delta \pi^{*}+\delta^{2} V(0)\right]$. Since the firm is indifferent between relenting and advertising $\overline{\bar{A}}$ when the state is $\overline{\bar{A}}-k$, setting these two expressions equal to each other,

$$
\delta^{2} V(k)=\left[\pi^{*}-\overline{\bar{A}}+\delta \pi^{*}+\delta^{2} V(0)\right]
$$

and solving for $\overline{\bar{A}}$ yields

$$
\overline{\bar{A}}=(1+\delta) \pi^{*}+\delta^{2}[V(0)-V(k)]
$$

Therefore, $\overline{\bar{A}} \geq(1+\delta) \pi^{*}$ since $V(0) \geq V(k)$ from the lemma. $\underline{G} \leq c$ implies that $\pi^{*}$ is equal to the one-period monopoly profit. Therefore, the level of advertising $\overline{\bar{A}}$ can exceed the one-period monopoly profit, which completes the proof of Claim 2.

Claim 3. During the war of attrition, the probability of relenting increases linearly with the level of advertising. 
Proof. During the mixed strategy phase, the firm is indifferent between relenting and increasing the level of advertising by $k$. On the one hand, by relenting, the firm avoids the large advertising costs and hastens the high-profit stream available at the beginning of the advertising war. On the other hand, relenting causes the firm to lose the chance of controlling the market for two periods. At state $A-k$, this indifference implies

$$
\delta^{2} V(k)=\left[\pi^{*}-A\right]+p(A)\left[\delta \pi^{*}+\delta^{2} V(0)\right]+[1-p(A)] \delta^{4} V(k)
$$

where with probability $p(A)$, the rival relents when the state is $A$. With probability $[1-p(A)]$, the rival does not relent and increases the level of advertising by $k$, in which case the firm always has the option of relenting. And similarly, at state $A$, indifference implies

$$
\delta^{2} V(k)=\left[\pi^{*}-(A+k)\right]+p(A+k)\left[\delta \pi^{*}+\delta^{2} V(0)\right]+[1-p(A+k)] \delta^{4} V(k)
$$

where with probability $p(A+k)$, the rival relents when the state is $A+k$. Subtracting (10) from (9) and solving for $[p(A+k)-p(A)]$ yields

$$
\Delta p=p(A+k)-p(A)=\frac{k}{\delta \pi^{*}+\delta^{2}\left[V(0)-\delta^{2} V(k)\right]}
$$

Notice that $p(A+k)>p(A)$, since from the lemma, $V(0) \geq V(k)$. This completes the proof of Claim 3.

The cost of staying in the advertising competition grows higher as advertising levels increase, but is compensated by an increased probability of winning the war if the firm stays in. As the firm moves to a higher level of advertising, the probability that the rival relents in the next period increases as well. Therefore, during the war of attrition, $V(\cdot)$ remains constant but $W(\cdot)$ is increasing. The increasing likelihood of the rival relenting in the next period cancels out the negative affect of the increased advertising cost on the one-period profit.

By backward induction, we can construct the profile of probabilities and derive the critical value $\bar{A}$. Note that $\Delta p$ is constant given the parameters of the model; it is not a function of the state. At $\overline{\bar{A}}$, the probability of relenting is equal to 1 , so at $\overline{\bar{A}}-k$, the probability of relenting is $(1-\Delta p)$. Therefore, from (11) the distance between $\overline{\bar{A}}$ and the level of advertising where the profile intersects zero the first time is

$$
\delta \pi^{*}+\delta^{2}\left[V(0)-\delta^{2} V(k)\right]
$$

Hence, the level of advertising where the profile hits zero is given by

$$
\hat{A}=\overline{\bar{A}}-\left\{\delta \pi^{*}+\delta^{2}\left[V(0)-\delta^{2} V(k)\right]\right\}
$$

plugging in the value for $\overline{\bar{A}}$ yields

$$
\hat{A}=\pi^{*}-\delta^{2}\left(1-\delta^{2}\right) V(k)
$$

Define $\bar{A}$ as the highest advertising that is less than or equal to $\hat{A}$ 


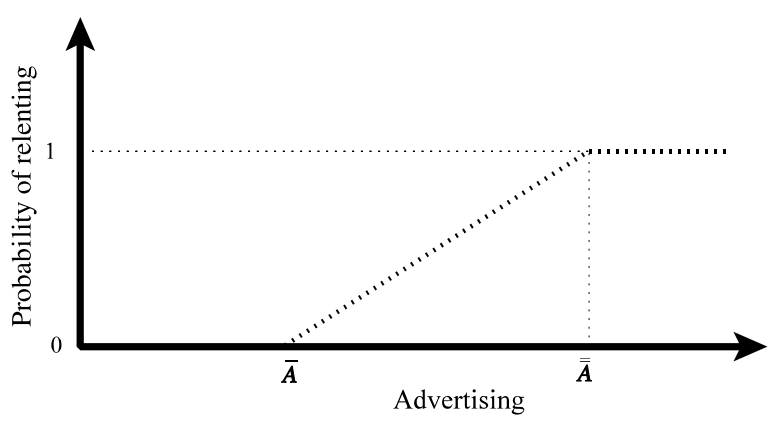

Figure 2

PROBABILITY OF ENDING AN ADVERTISING WAR

$$
\bar{A} \equiv \max _{A \in \mathbb{I} k}\{A \leq \hat{A}\}
$$

At a state $A \leq \bar{A}$, there is zero probability of relenting. Notice that although the probability of relenting is equal to zero at the state $\bar{A}$, the expected value of the game would be the same if the firm was to relent instead of increasing advertising to $\bar{A}+k$, since the rival's probability of relenting at $\bar{A}+k$ is greater than zero.

We have already discussed the conditions that $\bar{A}, \overline{\bar{A}}$, and $p(A)$ need to satisfy for equilibrium. $\overline{\bar{A}}$ is given by (8). The probabilities of relenting in the war of attrition phase, as shown in Figure 2, satisfy (9) and (11). $\bar{A}$ is given by (14) and (15). In the Appendix, we formally demonstrate that the strategies $\{R, R\}$ form a Markov-perfect equilibrium. We show that a firm would not choose to deviate from the strategies described by (6), neither on nor off the equilibrium path, given that the firm expects its rival to follow $R(A)$ in all states.

3.4. Concluding Remarks on the Model. This article shows that advertising can function as a device to coordinate consumer expectations in markets with consumption externalities. When consumers care about the purchasing behavior of other consumers, either due to social influences or network externalities, we may observe advertising competition even when consumers are fully rational and have common knowledge of the existence, characteristics, and prices of the products. We show that it is rational for consumers to use firms' advertising as a means of coordinating their expectations. In equilibrium, firms never have equal levels of advertising. Moreover, firms' equilibrium pricing strategies are such that it is always in an individual consumer's best interest to purchase the more heavily advertised brand. Therefore, advertising can indeed coordinate consumer expectations.

By using advertising, consumers can achieve coordination economies that may be unattainable using price information alone. The existence of consumption externalities implies that this is a nontrivial service. However, the value of this service depends on what would happen in its absence. In the absence of advertising, there are two possible equilibrium outcomes in consumers' purchasing decisions. They 
could coordinate on one of the brands ${ }^{15}$ or split between the two brands. ${ }^{16}$ In the first case, the coordination problem is solved even without advertising, so any resources spent on advertising will constitute a welfare loss. ${ }^{17}$ In the second case, however, advertising may help to achieve coordination economies, in which case it may be welfare enhancing.

But advertising costs are not perfectly aligned with the value of coordination. Advertising costs are related to the potential gains from coordination $[\bar{G}-\underline{G}]$. Firms are competing over which firm gets the coordinated demand. However, welfare is associated with the actual coordination gains $[\bar{G}-G(1 / 2)]$, which are related to welfare without any coordination device. The actual coordination gains need not be aligned with the cost spent on coordination.

Thus, even when consumers' demand is not coordinated in the absence of advertising, there is the possibility of "wasteful" advertising that is a total deadweight loss to society. For example, if all possible consumption externalities are exhausted when half the consumers purchase the good, then there are no actual gains from full coordination. Even with no coordination mechanism consumers will receive the full benefit from the product. In this case, although the uncoordinated demand does not lead to an inefficient outcome, there would still be advertising wars if consumers use advertising to coordinate their expectations. Consumers would buy the brand with higher advertising since they would expect that the brand with low advertising would not realize the consumption externalities.

Nevertheless, advertising can also lead to efficiency gains by promoting coordination of consumer expectations. If positive consumption externalities can be realized when a large percentage of the population uses the product, a failure to coordinate demand can result in efficiency losses. Advertising can coordinate consumer expectations about the purchasing decision of other consumers, and therefore increase welfare by making it possible to realize the consumption externalities.

\section{EMPIRICAL IMPLICATIONS}

In this article, we focus solely on a previously unanalyzed coordinating function of advertising in markets with consumption externalities. This simplifying approach helps to isolate the implications of this coordinating role for advertising in markets with consumption externalities. This type of coordinating advertising can be empirically differentiated from other types of coordinating advertising, analyzed by Bagwell and Ramey (1994a,b), by its price implications. Here, higher advertising gives a firm an advantage in price competition, whereas in the previous work, higher

\footnotetext{
15 This would almost always happen if firms have low marginal cost and consumers expected the higher-priced brand to receive more customers. It would also be the equilibrium outcome if they were playing a nonanonymous equilibrium where consumers simply expected a particular firm to have more customers.

${ }^{16}$ In an anonymous equilibrium, this would be the outcome if consumers expected the lowerpriced brand to receive more customers.

${ }^{17}$ To the extent that advertising revenues support valuable goods or services (such as television programs) or that consumers enjoy the advertisements themselves, the expenditures will contribute to welfare. Such issues are not analyzed here.
} 
advertising must be associated with lower prices. Price differences in products that are otherwise similar may be due to the expectations of consumers as to how widely each will be adopted. For example, the fact that Levis jeans, a heavily advertised brand, often sell for several times the price of very similar but unadvertised brands, may be due to this coordinating role of advertising in a market with consumption externalities.

This coordinating role for advertising suggests firms selling goods with consumption externalities have an additional incentive to advertise. Since effective coordinating advertising requires that consumers know that others have seen the advertising as well, advertisers of goods with consumption externalities would prefer one publicly observable advertisement to many privately observable advertisements. Thus, ceteris paribus, these firms would be willing to pay more to reach a large audience with a single advertisement. Using a data set which includes advertising during the Super Bowl, Chwe (1998) is able to test this directly. He finds that it is the advertisers of goods who are likely to exhibit positive consumption externalities that do in fact choose to advertise on the most popular television shows, and are willing to pay a premium to do so.

As demonstrated in the model, advertising as a mechanism for coordinating expectations can be quite expensive. Firms pay the cost of this device through their advertising expenses. At times, the one-period advertising expense can exceed the one-period monopoly profit. Consumers must also bear some of the cost of advertising indirectly through higher prices, because advertising competition reduces price competition. If marginal cost is sufficiently high $(c \geq \underline{G})$, firms compete through advertising alone. In this case, it is possible to have intense advertising competition while prices are stable at the monopoly price, an empirically observed phenomenon that has been difficult to explain theoretically; see Nichols (1951).

Also, notice that when advertising is being used as a coordination device, the firm with high advertising can induce consumers to coordinate on its product. Thus, firms' competition for market share takes the form of advertising competition, rather than competition through price or quality. This is in accord with the findings of Davies and Geroski (1997) who report that advertising plays a major role in the dynamics of market shares.

When advertising is being used solely as a coordinating device, the absolute level of advertising will have no effect on a firm's sales. What is important for coordination is the relative level of advertising compared to other firms. Even if advertising is also serving other roles, when it is also being used as a coordination device, there will be a discontinuity in the response of consumers to advertising. The empirical works of Lambin (1976) and Porter (1976) are suggestive of such an effect. This hypothesis can be tested directly by regressing sales on the level of advertising expenditure and advertising expenditure relative to other firms. A significant coefficient on relative advertising would be in line with the prediction of the model.

\section{DIRECTION FOR FUTURE RESEARCH}

This article demonstrates that even when consumers are fully rational, and have common knowledge of the existence, characteristics, and prices of the products, 
advertising can still have an important role to play. Advertising can function as a focal device to coordinate consumer expectations in markets with consumption externalities. This previously unexplored role for advertising has implications that go far beyond the repeat-purchase markets that we analyzed in this article. For instance, many markets with lock-in effects and brand loyalty also have consumption externalities. It is clear that the function of advertising that we develop here is also likely to be very important in these markets where past consumption affects current demand. Future work could examine the nature of advertising competition in such markets. Of particular interest would be how the incentive to charge a premium for the heavily advertised product that we explored in this article interacts with the incentive to charge a low introductory price that is typically found in models with lock-in effects and brand loyalty.

In markets with network externalities, problems of standardization on a particular technology or brand often arise. This suggests that the coordinating role of advertising may be used by firms in their attempts to win standardization battles. The firms will engage in advertising competition in order to coordinate consumers on their own brand. Such standardization battles through advertising are isomorphic to all-pay auctions. All bidders must pay their bids (their advertising expenses) and the highest bidder captures the prize (standardization on its brand). Thus, the literature on auctions may be able to shed some light on the advertising costs of standardization battles.

\section{APPENDIX}

A.1. Demonstration of Equilibrium. Here, we will show that the strategies defined in the response functions form a Markov-perfect equilibrium. That is, given that a firm expects its rival to follow the strategy given by $R(A)$, Equation (6), the best response of the firm is to play the $R(A)$ in all possible states of advertising, both on and off the equilibrium path. Firms have no incentive to deviate from the equilibrium strategies.

\section{LEMma. The valuation function $V(\cdot)$ is nonincreasing.}

Proof. From Equation (5), note that for a given $A, \pi(A ; \tilde{A})$ is nonincreasing in $\tilde{A}$. Take two state variables $\tilde{\tilde{A}}$ and $\tilde{A}$ such that $\tilde{\tilde{A}}<\tilde{A}$. Define $A^{*}$ as the optimal reaction to $\tilde{A}$ :

$$
V(\tilde{A})=\pi\left(A^{*} ; \tilde{A}\right)+\delta W\left(A^{*}, R\left(A^{*}\right)\right) \leq \pi\left(A^{*}, \tilde{\tilde{A}}\right)+\delta W\left(A^{*}, R\left(A^{*}\right)\right) \leq V(\tilde{\tilde{A}})
$$

The first inequality follows from the fact that $\pi(A ; \tilde{A})$ is nonincreasing in $\tilde{A}$, whereas the second comes from the fact that $A^{*}$ is the optimal reaction to $\tilde{A}$, and not to $\tilde{\tilde{A}}$. This completes the proof of the lemma.

In the equilibrium strategy $R(A)$, the firm does not match the level of advertising of its rival in any state. If the firm advertises the same amount as its rival, the firms will engage in fierce price competition resulting in low profits. Define $\left.V(A)\right|_{A^{\prime}}$ as the expected present value of the game to the firm whose turn it is to choose advertising, 
given that it plays $A^{\prime}$ rather than its equilibrium strategy. If firms are in the pure strategy phase, the expected value of the game if the firm matches the rival's advertising is given by

$$
\left.V(A)\right|_{A}=\tilde{\pi}-A+\delta^{2} V(A+k)
$$

since the rival would increase advertising by $k$ and the firm would have to wait for two periods to receive $V(A+k)$. If it instead follows its equilibrium strategy,

$$
V(A)=\pi^{*}-(A+k)+\delta^{2} V(A+2 k)
$$

thus

$$
V(A)-\left.V(A)\right|_{A}=\left(\pi^{*}-\tilde{\pi}\right)-k+\delta^{2}[V(A+2 k)-V(A+k)]
$$

Note that $V(A+x k)$ with $x \in \mathbb{I}$ is a function of $A, x, k, \bar{A}$, and the number of periods until $\bar{A}, \tau$. As we vary $k$, both $\bar{A}$ and $\tau$ evolve discontinuously (since $\bar{A} \in \mathbb{I} k$ and $\tau \in \mathbb{I}$ ), but not independently, because $\tau$ is defined by $\tau k=\bar{A}-A$. When we vary $k$ but hold $\tau$ constant, $\bar{A}$ evolves continuously so that we can restrict our attention to jumps in $\tau$. Although $\tau$ evolves discontinuously, it only jumps when the expected present value of profits at $\tau^{\prime}$ and $\tau^{\prime \prime}$ are the same. The choice of $\tau$ will change when $\left.V(\cdot)\right|_{\tau^{\prime}}>$ $\left.V(\cdot)\right|_{\tau^{\prime \prime}}$. So, $V(A+x k)$ is continuous in $k$. Note also that neither $\pi^{*}$ nor $\tilde{\pi}$ depend on $k$. The implication of this is that for small $k$, Equation (A.1) is positive, and therefore in the pure-strategy phase, it is always better for a firm to out-advertise its rival than to set the same level of advertising.

If the firms are in the mixed-strategy phase, the expected value of the game from matching the rival's advertising would be

$$
\left.V(A)\right|_{A}=\tilde{\pi}-A+\delta W(A, R(A))
$$

where $W(A)$ is the expected value of the game over the equilibrium strategies of the rival when the rival is about to move. In this case, advertising zero is always better than matching the rival's advertising. To see this, note that when the advertising is equal to $A-k$, the firms are indifferent between advertising zero and increasing advertising by $k$

$$
\left.V(A-k)\right|_{0}=\delta^{2} V(k)=\pi^{*}-A+\delta W(A, R(A))=\left.V(A-k)\right|_{A}
$$

When the state is $A$, the expected value of the game from moving to zero level of advertising $\left.V(A)\right|_{0^{\prime}}$, is also equal to $\delta^{2} V(k),($ A.2) implies that lowering advertising all the way to zero yields profits which are $\left[\pi^{*}-\tilde{\pi}\right]>0$ above the profits gained by matching the rival's advertising.

Therefore, matching the rival's advertising can never be a best response. Likewise, if the firm considers advertising less than its rival, it would always be better off by lowering it all the way to zero. When the firm advertises less than its rival, the rival captures the coordinated demand. The firm gets a one-period loss equal to its level of advertising, just like in the case when it matches the rival's advertising. Therefore, the above arguments are also valid for the case where the firm is contemplating lowering the level of advertising. 
Likewise, the firm will never raise advertising to a level greater than $\overline{\bar{A}}$. If it did so, its rival would relent in the next period yielding expected profits that are less than or equal to

$$
(1+\delta) \pi^{*}-A+\delta^{2} V(0)<(1+\delta) \pi^{*}-\overline{\bar{A}}+\delta^{2} V(0)
$$

From (7), the right-hand side is equal to the value of the game if the firm chooses advertising of zero. So advertising zero is always preferable to raising advertising to a level greater than $\overline{\bar{A}}$.

During the pure-strategy phase, the firm will never choose to advertise zero. If the firm increases advertising by $k$, which is the best response from (6), the expected value of the game is given by

$$
\left.V(A)\right|_{A+k}=\pi^{*}-(A+k)+\delta^{2} V(A+2 k)
$$

The option of relenting yields an expected value of the game equal to $\delta^{2} V(k)$. However, in the pure-strategy phase, the maximum value $(A+k)$ can take is $\hat{A}=\pi^{*}-\delta^{2}\left(1-\delta^{2}\right) V(k)$, and, therefore, the lowest the expected value of the game can be when the firm increases advertising by $k$ is given by

$$
\left.V(A)\right|_{A+k} \geq \pi^{*}-\left[\pi^{*}-\delta^{2}\left(1-\delta^{2}\right) V(k)\right]+\delta^{2} V(A+2 k)=\delta^{2}\left(1-\delta^{2}\right) V(k)+\delta^{2} V(A+2 k)
$$

$V(A+2 k)$ must be greater than or equal to $\delta^{2} V(k)$ because relenting will always be an option for the firm. Therefore,

$$
\left.V(A)\right|_{A+k} \geq \delta^{2} V(k)
$$

Therefore, during the pure-strategy phase, where firms out-advertise each other with certainty, the firm would not be better off by decreasing the level of advertising to zero.

It only remains to be shown that the firm would never choose to increase the level of advertising by more than $k$, neither in the mixed-strategy phase nor the purestrategy phase. In every state in the mixed-strategy phase, the firm has the same expected value of the game, because it is always indifferent between increasing advertising and advertising zero. Therefore, the firm does not strictly prefer to increase the level of advertising by more than $k$. Furthermore, during the purestrategy phase, the firm would not choose to increase the level of advertising by more than $k$. If the firm increases the level of advertising by more than $k$, to a state where the game is still in the pure-strategy phase, the increased advertising expense would lower the one-period profit and induce the rival to increase the level of advertising even more. The lemma shows that the expected present value of the game cannot be greater due to an increase in the rival's advertising. If the firm increases advertising so much that the game enters the mixed-strategy phase, the value of the game would just be $\delta^{2} V(k)$, which is equal to the expected value of the game if the firm were to relent and move to the beginning of the competition, and that has already been shown not to be superior to the equilibrium strategy. Therefore, in the pure-strategy phase, the firm has no incentive to deviate from the equilibrium strategy of increasing the level of advertising by $k$. 
A.2. Endogenous Timing. Here, we relax the exogenous timing assumption while maintaining the short-run commitment to the level of advertising. We show that when consumers coordinate on the low-priced brand when advertising levels are equal or when consumers coordinate on the high-priced brand when advertising levels are equal and $\underline{G} \leq c$, then with endogenous timing firms will choose to be in the alternating move game. Consider the entry decision of a new firm into a monopolistic market. The entrant must decide when to penetrate the market. It has two options. The firm can enter the market in a period when the incumbent has no commitment to advertising and hence decide on the advertising simultaneously with the incumbent. It also has the alternative of entering the market when the incumbent is already committed to the level of advertising, which would put the firms into the alternating move game. In the discussion that follows, we show that the expected present value of the simultaneous move game is less than the expected present value of the alternating move game. Therefore, the entrant would strictly prefer the alternating move game to the simultaneous move game. The incumbent is also better off in the alternating move game, although the incumbent would prefer that the other firm not enter at all.

If the entrant enters when the incumbent is committed to a level of advertising, the firms will be in the alternating move game and the entrant will receive the value of the game, $V(A)$.

Claim 4. In the alternating move game, when the firm is about to move in its advertising decision, the expected value of the game at any state of the advertising competition has a lower bound given by $V(\cdot) \geq \delta^{2}\left(\pi^{*}-2 k\right)>0$.

Proof. Since the firm always has the option of advertising zero forever, the expected present value of the game at any state has to be greater than or equal to zero when it is the firm's turn to move in its advertising decision. Furthermore, if the firm relents, the rival would then increase advertising to $k$ so that relenting has the value $\delta^{2} V(k)$ where

$$
V(k)=\pi^{*}-2 k+\delta^{2} V(3 k)
$$

Therefore,

$$
V(k) \geq \pi^{*}-2 k
$$

Since relenting is always an option, for small $k$ (A.4) implies

$$
V(\cdot) \geq \delta^{2}\left(\pi^{*}-2 k\right)>0
$$

This completes the proof of Claim 4.

If the firm enters the market when the incumbent is not committed to its level of advertising, the firms will be in the simultaneous move game. When firms simultaneously decide on the level of advertising, there is no pure-strategy Nash equilibrium. To see this, note that before advertising expenses, the present value of the maximum payoff a firm can get in two periods is $(1+\delta) \pi^{*}$. Suppose that there was 
a pure-strategy equilibrium where the firm chose $A<(1+\delta) \pi^{*}$. In that case, the best response of the rival would be to advertise $A+k$ if $(A+k) \leq(1+\delta) \pi^{*}$. However, if the rival advertises $A+k$, it would no longer be optimal for the firm to advertise $A$. It would be better off advertising zero to avoid the losses incurred due to the advertising expense. If $(A+k)>(1+\delta) \pi^{*}$, the rival would choose zero as its level of advertising. If the rival chooses zero, however, for small $k$, it would no longer be optimal for the first firm to Advertise $A$.

Since in the simultaneous move game there is no pure-strategy Nash equilibrium, let us now focus attention on symmetric mixed-strategy equilibria. Consider the case where there is a positive probability $q_{A}>0$ for the firm to set the level of advertising equal to $A$. Furthermore, assume that the probability of setting advertising to $A-k$ is $q_{A-k}=0$. Once the firm advertises $A$, if the rival out-advertises the firm $(\tilde{A}>A)$, the firm would have been better off by setting a lower advertising, $A-k$. If the rival matches the level of advertising $(\tilde{A}=A)$, the firm would have preferred to set advertising $A-k$, since when the levels of advertising are the same, the solution to the simultaneous price game yields zero profits. If the rival advertises below the advertising of the firm $(\tilde{A}<A)$, then $\tilde{A}$ is also smaller than $A-k$ since we initially assumed $q_{A-k}=0$, and the firm would have preferred to advertise $A-k$. Therefore, whatever the rival does, the firm would prefer $A-k$ to $A$. So, by contradiction, when $q_{A}>0, q_{A-k}$ has to be greater than zero as well. If for some $A, q_{A}>0$, we can iterate and show that the probability of advertising zero must also be greater than zero. The value of the two-period stage game is zero when advertising is set to zero. In the mixed-strategy equilibrium, the firms are indifferent between setting any level of advertising where the probability is greater than zero. So, the expected present value of the simultaneous move game is equal to zero. ${ }^{18}$

If the entrant penetrates the market when the incumbent is not committed to a level of advertising, the firms find themselves in the simultaneous move game. In the simultaneous move game, however, the expected present value of the game is zero, whereas in the alternating move game the expected present value of the game is strictly greater than zero. Therefore, the entrant will choose to penetrate the market at some period when the incumbent is already committed to advertising. This puts the firms into the alternating-move game where the expected present value of the game is strictly greater than zero.

A.3. Existence of Equilibrium. A lower bound on $V(k)$ is given by (A.4). An upper bound can be found from (A.3) by noting that $V(k) \geq V(3 k)$, which yields, $V(k) \leq\left(\pi^{*}-2 k\right) /\left(1-\delta^{2}\right)$. Define a function $\mathscr{V}(A, V(k))$, over this range of $V(k)$, in the same way that $V(A)$ is defined. That is, $\mathscr{V}(A, V(k))$ is equal to the expected present value of profits when a firm is about to choose advertising, the state variable is $A$, and both firms are expected to play their equilibrium strategies (6). This is done by solving forward until a state $A \geq \bar{A}$, at which point the expected present value of profits is equal to $\delta^{2} V(k)$. This yields

\footnotetext{
${ }^{18}$ Note that firms' advertising decisions in the simultaneous move game are isomorphic to a sealed-bid all-pay auction. Thus, the results of the auction literature can be applied to find the cost of advertising in this case. See, for example, Baye et al. (1993, lemma 1) for a similar result.
} 
(A.5)

$$
\begin{aligned}
& \mathscr{V}(A, V(k))= \\
& \begin{cases}\delta^{2} V(k) & \text { if } A \geq \bar{A} \\
\pi^{*}-(A+k)+\delta^{2}\left[\pi^{*}-(A+3 k)\right]+\cdots+\delta^{20}\left[\pi^{*}-\bar{A}\right]+\delta^{2 v+4} V(k) & \text { if } A<\bar{A} \text { and } A=\bar{A}-(2 v+1) k \\
\pi^{*}-(A+k)+\delta^{2}\left[\pi^{*}-(A+3 k)\right]+\cdots+\delta^{2 v-2}\left[\pi^{*}-(A-k)\right]+\delta^{2 v+2} V(k) & \text { if } A<\bar{A} \text { and } A=\bar{A}-2 v k\end{cases}
\end{aligned}
$$

where $v \in \mathbb{I I}$.

From (A.5), if the critical values $\bar{A}, \overline{\bar{A}}$, and the probability profile $p(A)$ exist, and if $V(k)$ exists, then $\mathscr{V}(A, V(k))$ exists for all $A \in \mathbb{I} k$. Taking the existence of $V(k)$ as given for a moment, it is possible to show the existence of the critical value $\overline{\bar{A}}$.

Claim 5. There exists a set $K$ containing an infinity of (small) positive real numbers such that $k \in K$ implies $\overline{\bar{A}}=(1-\delta) \pi^{*}+\delta^{2}[V(0)-V(k)] \in \mathbb{I} k$.

Proof. From (A.5), the existence of $V(k)$ implies that $V(0)$ also exists. Therefore, $\overline{\bar{A}} \geq(1+\delta) \pi^{*}$ since $V(0) \geq V(k)$. Given the equilibrium strategies, $V(k)=\pi^{*}-2 k+$ $\delta^{2} V(3 k) \geq \pi^{*}-2 k$. The highest profit that a firm can expect to earn in any period is $\pi^{*}$, so $V(0) \leq \pi^{*} /(1-\delta)$. Therefore, from (8),

$$
\overline{\bar{A}} \leq(1+\delta) \pi^{*}+\delta^{2}\left[\frac{\pi^{*}}{1-\delta}-\pi^{*}+2 k\right]
$$

So, $\overline{\bar{A}}$ is bounded

$$
\overline{\bar{A}} \in\left[(1+\delta) \pi^{*}, \frac{\left(1-\delta^{2}+\delta^{3}\right) \pi^{*}}{1-\delta}+2 \delta^{2} k\right]
$$

Now, we have to show continuity of $\overline{\bar{A}}$ with respect to $k$. Since the highest profit a firm can get in each period is $\pi^{*}, V(k) \leq \pi^{*} /(1-\delta)$ from Equation (14) implies that for small $k, k<\bar{A}$. Therefore, $V(k)$ can be easily found from (A.5) by noting that in equilibrium, $V(k)=\mathscr{V}(k, V(k))$. From the argument given in Section A.1, in the purestrategy phase $V(\cdot)$ is continuous in $k$. Therefore, for small $k$, both $V(k)$ and $V(0)$ are continuous in $k$. Therefore, $\overline{\bar{A}}$ is also continuous in $k$. Since $\overline{\bar{A}}$ is bounded and continuous in $k$,

$$
\lim _{k \rightarrow 0}\left(\frac{\overline{\bar{A}}}{k}\right)=\infty
$$

and $\overline{\bar{A}} / k$ crosses an infinite number of integers as $k \rightarrow 0$, which completes the proof of Claim 5.

So, as $k \rightarrow 0$ or for $k \in K, \overline{\bar{A}}$ exists. From this, the argument presented in the text shows that $\bar{A}$ and the probability profile $p(A)$ exist. Therefore, in order to prove the existence of equilibrium, it only remains to show that there exists a fixed point in $V(k)$. That is, it must be shown that $\mathscr{V}(k, V(k))=V(k)$ is satisfied for some value of $V(k)$ in the possible range. This will be done by showing first that $\mathscr{V}(A, V(k))$ is continuous in $V(k)$. Then, it will be shown that $\mathscr{V}(k, V(k))$ maps the possible range of $V(k)$ back into itself. Together, these properties will guarantee a fixed point and hence the existence of equilibrium. 
Continuity. The definition of $\mathscr{V}(A, V(k))$ depends on the level of the endogenous variable $\bar{A}$, which evolves discontinuously with $V(k)$ since $\bar{A} \in \mathbb{I} k$. However, as we vary $V(k)$, the choice of $\bar{A}$ will switch from $A^{\prime}$ to $A^{\prime \prime}$ when the expected value of the game is the same under each choice. Therefore, $\mathscr{V}(A, V(k))$ is continuous in $V(k)$.

Lower bound on $\mathscr{V}(k, V(k))$. Evaluate $\mathscr{V}(A, V(k))$ at $A=k$. For small $k$, this implies that $A<\bar{A} . V(k)>0$ and (14) yields $\bar{A}<\pi^{*}$ for small $k$. From (A.5) this means that $\mathscr{V}(k, V(k))>\pi^{*}-A-k=\pi^{*}-2 k$ since all the other terms on the right-hand side of (A.5) are positive.

Upper bound on $\mathscr{V}(k, V(k))$. Notice that the upper bound $V(k) \leq\left(\pi^{*}-2 k\right) /$ $\left(1-\delta^{2}\right)$ satisfies

$$
\frac{\pi^{*}-2 k}{1-\delta^{2}}=\sum_{j=0}^{\infty} \delta^{2 j}\left(\pi^{*}-2 k\right)=\sum_{j=0}^{n-1} \delta^{2 j}\left(\pi^{*}-2 k\right)+\delta^{2 n}\left(\frac{\pi^{*}-2 k}{1-\delta^{2}}\right)
$$

For $k<\bar{A}$, compare (A.6) with (A.5). All the summation terms in the definition of $\mathscr{V}(k, V(k))$ are less than or equal to the summation terms in (A.6). Moreover, the final term in (A.5) is less than or equal to the final term in (A.6), since $V(k) \leq\left(\pi^{*}-2 k\right) /\left(1-\delta^{2}\right)$. Therefore, $\mathscr{V}(k, V(k)) \leq\left(\pi^{*}-2 k\right) /\left(1-\delta^{2}\right)$.

$\mathscr{V}(k, V(k))$ is a continuous function of $V(k)$ mapping $V(k) \in\left[\pi^{*}-2 k,\left(\pi^{*}-2 k\right) /\right.$ $\left.\left(1-\delta^{2}\right)\right]$ into $\left(\pi^{*}-2 k,\left(\pi^{*}-2 k\right) /\left(1-\delta^{2}\right)\right]$. Therefore, there exists a value $V(k)$ such that $\mathscr{V}(k, V(k))=V(k)$, which proves the existence of equilibrium.

\section{REFERENCES}

Bagwell, K., And G. Ramey, “Advertising and Coordination,” Review of Economics Studies 61 (1994a), 153-72.

, AND — "Coordination Economies, Advertising, and Search Behavior in Retail Markets," American Economic Review 84 (1994b), 489-517.

Baye, M., D. Kovenock, And C. De Vries, "Rigging the Lobbying Process: An Application of the All-Pay Auction,” American Economic Review 83 (1993), 289-94.

Becker, G., "A Note on Restaurant Pricing and Other Examples of Social Influences on Price," Journal of Political Economy 99 (1991), 1109-16.

— , AND K. MurPhy, “A Simple Theory of Advertising as a Good or Bad," Quarterly Journal of Economics 108 (1993), 941-64.

Butters, G., "Equilibrium Distribution of Prices and Advertising," Review of Economic Studies 44 (1977), 465-92.

Chwe, M., "Believe the Hype: Solving Coordination Problems with Television Advertising," mimeo, University of Chicago, January 1998.

Davies, S., And P. Geroski, "Changes in Concentration, Turbulence, and Dynamics of Market Shares," Review of Economics and Statistics 79 (1997), 383-91.

Dixit, A., AND V. Norman, “Advertising and Welfare,” Bell Journal of Economics 9 (1978), 1-17.

Enrico, R., And J. Kornbluth, The Other Guy Blinked: How Pepsi Won the Cola Wars (New York: Bantam Books, 1986).

FARrell, J., AND G. SAlONER, "Standardization, Compatibility, and Innovation," RAND Journal of Economics 16 (1985), 70-83.

Frank, R., Choosing the Right Pond: Human Behavior and the Quest for Status (Oxford: Oxford University Press, 1985).

Galbraith, J. K., The New Industrial State (Boston: Houghton Mifflin, 1967). 
Grossman, G., AND C. Shapiro, “Informative Advertising with Differentiated Products," Review of Economic Studies 51 (1984), 63-82.

HalPerin, A., "Price Competition and Inflation," mimeo, Massachusetts Institute of Technology, 1990.

Ishigaki, H., "Repetitive Advertising to Deter New Entry,” mimeo, Aomori Public College, 1999.

Kinlstrom, R., AND M. Riordan, “Advertising as a Signal,” Journal of Political Economy 92 (1984), 427-50.

Lambin, J., Advertising, Competition and Market Conduct in Oligopoly Over Time (Amsterdam: North-Holland, 1976).

Maskin, E., And J. Tirole, “A Theory of Dynamic Oligopoly, II: Price Competition, Kinked Demand Curves and Edgeworth Cycles," Econometrica 56 (1988), 571-99.

Meurer, M., AND D. Stahl, "Informative Advertising and Product Match," International Journal of Industrial Organization 12 (1994), 1-19.

Milgrom, P., And J. Roberts, "Price and Advertising Signals of Product Quality," Journal of Political Economy 94 (1986), 796-821.

Nelson, P., "Advertising as Information," Journal of Political Economy 82 (1974), 729-54.

Nichols, W., Price Policies in the Cigarette Industry (Nashville, TN: Vanderbilt University Press, 1951).

Pastine, I., And T. Pastine, "Coordination in Markets with Consumption Externalities: The Role of Advertising and Product Quality," mimeo, Bilkent University, February 1999.

PANetTieri, J., "Like a Gale Force," Information Week 27 (1995), 46-56.

Pesendorfer, W., "Design Innovation and Fashion Cycles," American Economic Review 85 (1995), 771-92.

Porter, M., "Interbrand Choice, Media Mix and Market Performance," American Economic Review 66 (1976), 398-406.

Rebello, K., AND M. Kuntz, "Feel the Buzz: Win95's marketing blitz will be loud and costly," Information Week 28 (1995), 31.

Robert, J., And D. Stahl, "Informative Price Advertising in a Sequential Search Model," Econometrica 61 (1993), 657-86.

Rohlfs, J., “A Theory of Interdependent Demand for a Communications Service," Bell Journal of Economics 5 (1974), 16-37.

Schelling, T., Micromotives and Macrobehavior (New York: Norton, 1978).

Solow, R., "The New Industrial State or Son of Affluence," Public Interest 9 (1967), 100-8.

Stahl, D., "Oligopolistic Pricing and Advertising," Journal of Economic Theory 64 (1994), 162-77.

Stegeman, M., "Advertising in Competitive Markets," American Economic Review 81 (1991), 210-23. 
